\title{
Evaluation of the Differentiated Instruction Approach for an Electrical Engi- neering Circuit Analysis Module
}

\section{Dr. Craig A. Chin, Kennesaw State University}

Craig A. Chin received his Ph.D. in electrical engineering from Florida International University in 2006. $\mathrm{He}$ is currently an Associate Professor in the electrical engineering department at Kennesaw State University. His research interests include biomedical signal processing, machine learning, and differentiated instruction techniques applied to engineering education.

\section{Dr. Roneisha Wynette Worthy, Kennesaw State University}

Roneisha W. Worthy, $\mathrm{PhD}$, is an assistant professor in civil engineering at Southern Polytechnic College of Engineering and Engineering Technology at Kennesaw State University. Her research interests include increasing the participation of minorities, women and other underrepresented groups in engineering. Dr. Worthy focuses much of her research efforts in the area of community engagement and STEM pipeline development. She works to connect P-12 educators and students with STEM professors, students and departments at KSU.

\section{Prof. Donna Colebeck, Kennesaw State University}

Donna Colebeck is a Senior Lecturer of Foundation Studies and Studio Art in the School of Art and Design, College of the Arts at Kennesaw State University. She has s Master of Fine Arts from Rochester Institute of Technology. Research interests include experiential and other modes of learning, instructional practices and application/implementation from an interdisciplinary perspective. 


\title{
Evaluation of the Differentiated Instruction Approach for an Electrical Engineering Circuit Analysis Module
}

\begin{abstract}
Differentiated instruction (DI) is a teaching approach in which learning experiences are designed and adapted to meet students' individual and diverse needs in order to facilitate student success. This approach has been advocated in K-12 classes, but has not been used extensively in college courses and STEM/Engineering courses in particular. When one considers that significant student diversity still exists beyond high school graduation, a strong argument can be made for the benefit of implementing DI strategies in a college course environment. This paper presents the findings of an initial implementation of DI for a module of a circuit analysis course. This implementation involved diversifying course content and the learning process based on formative assessments of student readiness. The effectiveness of this approach was evaluated using a student survey and test scores. The student survey indicates that the majority of students had a positive assessment of their learning experience using the DI approach. The test results of the DI group were compared to the test results of a non-DI group using an independent samples t-test. T-test results did not indicate a statistical improvement in test results for the treatment group over the control group. The instructor evaluation of DI is that it has the potential to improve student performance based on the more individualized nature of the teaching approach, but a potential impediment to the successful implementation of this approach is the data acquisition and analysis tasks associated with formative assessment, which may become prohibitively burdensome with large class sizes and few contact hours. One way to overcome this impediment is to devise ways to provide feedback on a larger scale than on an individual basis and devise methods to automate the differentiation process.
\end{abstract}

\section{Introduction}

The motivation for differentiated instruction (DI) is based on the observation that any class environment will consist of learners of different abilities, interests, learning styles and cultural backgrounds. This implies that learners will respond to instruction differently, and the one-sizefits-all teaching approach, commonly utilized in college classrooms, is less than optimal from the standpoint of student learning. DI acknowledges the diverse characteristics of the individual learner by designing learning experiences that are adapted to meet the unique learning needs of a student with the expectation of improving student success compared to the one-size-fits-all paradigm. In the DI model [1], an instructor can differentiate instruction in the following areas: content (the information used to reach learning goals), process (the mechanism by which students interact with content), product (how students show what they understand and can do) and environment (the climate or tone of the classroom). Instructional differentiation in these four areas should be based on the student's readiness (student proximity to specified learning goal), interests (the passions, affinities, kinships that motivate learning) and learner profile (a student's preferred approaches to learning).

DI is used primarily in K-12 learning environments, and the effectiveness of this approach has been supported by both learning theory and empirical research. In [2], it is shown that 
differentiation based on student readiness aligns with Vygotsky's theory describing a zone of proximal development [3] and that achievement gains have been experienced for students in effectively differentiated classrooms. The zone of proximal development refers to an optimal level of challenge for a task that a student must learn. At this optimal level, a student cannot complete the task successfully on his or her own but will require instructional scaffolding or help from someone else. If the task is too hard, the student will struggle and may give up. If the task is too easy the student will complete the task with little effort and may become demotivated. With the DI approach, it is more likely that instruction will align with a student's zone of proximal development as opposed to the one-size-fits-all approach. Also, in [2], it is shown that differentiation according to student interest contributes to a sense of competence and selfdetermination in learners, while differentiation based on learner profile results in improved achievement and attitude gains in students from a wide range of cultural groups.

While a K-12 classroom environment will probably possess higher levels of student variance in the areas of readiness, interest and learner profile, there will still be significant variance in the college classroom. As published by the National Center for Education Statistics (NCES) [4], there is significant diversity in the undergraduate student body based on ethnicity: $57.9 \%$ (White), 16.1\% (Black), 16.0\% (Hispanic), 5.6\% (Asian), 0.9\% (American Indian), 0.5\% (Pacific Islander) and 3.0\% (> 2 races). There is also significant diversity in undergraduate age groups: $9.0 \%$ ( $\leq 18$ years), $47.2 \%$ (19 - 23 years), $18.4 \%$ ( $24-29$ years), $14.0 \%$ (30 - 39 years) and $11.4 \%$ ( $\geq 40$ years). Also, $11.1 \%$ of undergraduates report that they have some type of disability. Given these statistics, a strong case can be made for implementing DI in a college classroom.

While DI has not been utilized extensively in higher education, there are a few examples in which this approach has been attempted for undergraduate and graduate courses. In [5] - [8], DI has been used for a graduate education course, an undergraduate mathematics course, an undergraduate education psychology course and an undergraduate education course, respectively. In [5], content and process were differentiated according to student readiness and product was differentiated according to interest. In [6], content, process and product were differentiated on a per unit basis, based on readiness, interest and learner profile data collected from pre-assessments, formative assessments and learning style inventories. The authors of [7] used learner profile surveys to differentiate process for the students, while the author of [8] used Kolb's learning styles to differentiate process. For the studies conducted in [6] - [8], the impact of DI was assessed statistically by examining student grades in a pre-test versus post-test comparison or an experimental versus control group comparison. Experimental results in [6], [7] show a statistically significant improvement in student performance pre-test versus post-test and experiment versus control, respectively. However, the results of [8] show no statistical improvement in student performance. The DI approach was also assessed qualitatively using student evaluations in [5] - [7]. These evaluations reveal that students had a favorable perception of DI in all the studies.

The limited application of DI in college environments has produced encouraging results. These results have motivated investigating applying DI to an engineering course environment and a circuit analysis course, in particular. The purpose of this investigation is to assess the impact of implementing DI strategies on student readiness/performance and student attitudes towards 
instruction in an engineering course environment. A secondary purpose is to assess the difficulties associated with implementing DI in engineering course environments.

\section{Methods}

\subsection{Instructional Design}

DI strategies were implemented in a single module of a circuit analysis course taught to a class section of 55 students. The objective of this module is to enable each student to use nodal and mesh analysis techniques to find voltages and currents in a complex DC circuit. Over several semesters, my hypothesis, based anecdotal assessment of student performance, is that poor student performance may be attributed to two factors: the inadequate mastery of prerequisite knowledge required for this module by some students (student readiness), and the diversity of engineering majors required to take this course (variance in student interests).

As an initial attempt in applying DI to remedy these potential causes of poor student performance, I sought to use student readiness as the primary criterion for differentiation. DI strategies were used to differentiate content and process for each student as they interacted with learning tasks in an online learning management system. These learning tasks were used to assess student readiness, which would in turn serve to differentiate content and process for the future learning of each student.

The first learning task in this module was an online pre-class quiz that was designed to assess student mastery of prerequisite knowledge necessary for the module (Figure 1). An incorrect response to a question in this quiz results in the student being directed towards remedial material related to that question. In this way, content required for student reading was differentiated based on their level of mastery of the module prerequisite concepts.

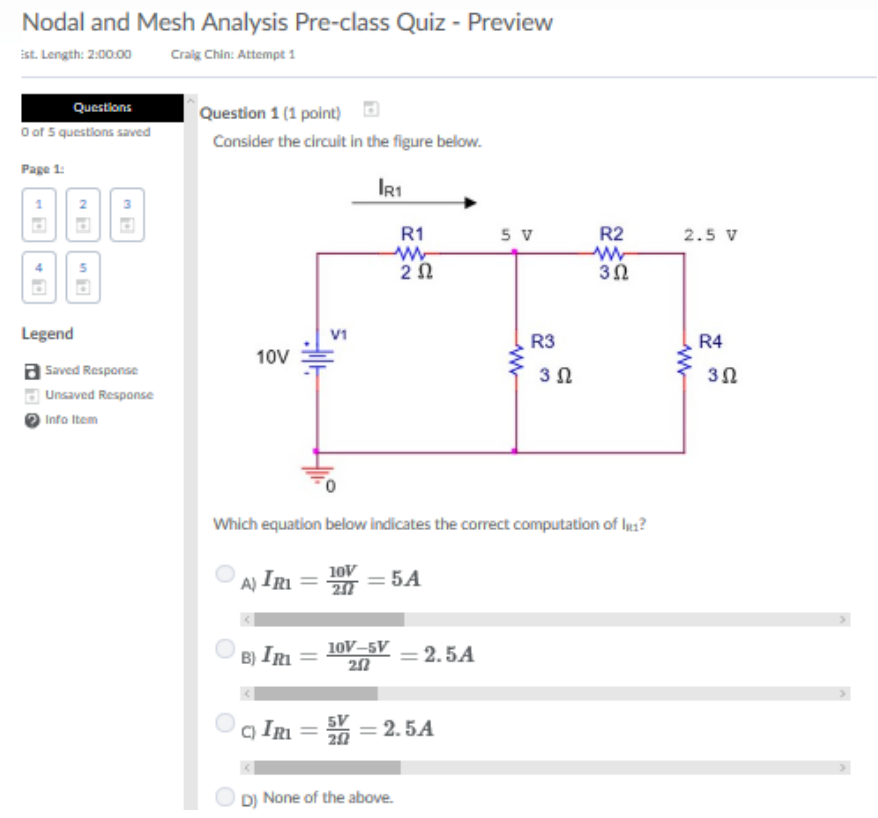

Figure 1 - Screenshot of Question 1 of Pre-class Quiz 
After teaching the nodal and mesh analysis techniques using lectures and instructor-led demonstrations, an online formative assessment multiple choice quiz was given to assess student proficiency in the areas of nodal and mesh analyses. The answers to the formative assessment were used as a guide to differentiate the homework assignment given to each student. For example, if a student performed poorly on either nodal or mesh analysis questions, there would be a larger proportion of basic nodal or mesh analysis questions in the homework assignment. If a student performed poorly on both nodal and mesh questions, his/her homework assignment will consist of only basic nodal and mesh analysis questions. If a student answered all formative assessment questions correctly, then his/her homework assignment would include more challenging analysis questions that would serve do deepen their understanding of these analyses. In this way, the formative assessment was used as the data source on student readiness that determined how the learning process was differentiated midway through the module. This ensured that homework questions were better aligned according to Vygotsky's zone of proximal development.

In addition to the modifications mentioned, a collaborative assignment was given at the end of the module. During this class period, students were divided into groups of three and were asked to solve problems similar in complexity to the problems found on the end-of-module test. This promoted peer-to-peer interaction and instructor-to-group interaction resulting in a different learning environment from the instructor-led approach. This was done to meet the learning preferences of students who may have a different learning profile.

\subsection{Experimental Design}

The effectiveness of the DI approach was evaluated using a student survey and end-of-module test scores. The survey was given to the class at the end of the module to poll student opinion as to whether the activities used in the module aligned well with the differentiation objectives detailed in the Instructional Design section. The end-of-module test scores of the section exposed to DI strategies were compared with the end-of-module test scores of a class section of 72 students in which no DI strategies are implemented. This comparison was performed using an independent samples t-test.

\section{Results}

\subsection{Survey Results}

The survey required that students express their level of agreement with three statements that assessed the effectiveness of the differentiation strategies used in the module. Level of agreement is measured using a five-point Likert scale (Table 1). Students were also asked to give an overall assessment of their experience interacting with DI in the module (Figure 2).

\subsection{End-of-Module Test Score Results}

The results of the independent samples t-test are given in Table 2. Note that the designation DI refers to the class section exposed to DI strategies and the designation NDI refers to the class section in which no DI strategies were used. 
Table 1 - Summary of Student Responses to Survey Questions Related to the Effectiveness of DI Strategies

\begin{tabular}{|c|c|c|c|c|c|c|c|c|c|}
\hline Question & \begin{tabular}{|l|} 
Strongly \\
Agree
\end{tabular} & Agree & & Undecid & & Disagre & & \begin{tabular}{|l} 
Strongly \\
Disagree
\end{tabular} & Total \\
\hline $\begin{array}{l}\text { 1. Learning material was provided based on } \\
\text { my understanding of the topic. }\end{array}$ & $36.96 \% \quad 17$ & $56.52 \%$ & 26 & $2.17 \%$ & 1 & $4.35 \%$ & 2 & $0.00 \%$ & 46 \\
\hline $\begin{array}{l}\text { 2. Activities and assignments were } \\
\text { individualized based on my understanding } \\
\text { of the material. }\end{array}$ & $41.30 \% \quad 19$ & $50.00 \%$ & 23 & $4.35 \%$ & 2 & $4.35 \%$ & 2 & $0.00 \%$ & 46 \\
\hline $\begin{array}{l}\text { 3. Assessment is used before, during and } \\
\text { after learning to guide instruction. }\end{array}$ & $43.48 \% \quad 20$ & $34.78 \%$ & 16 & $10.87 \%$ & 5 & $10.87 \%$ & & $0.00 \%$ & 46 \\
\hline
\end{tabular}

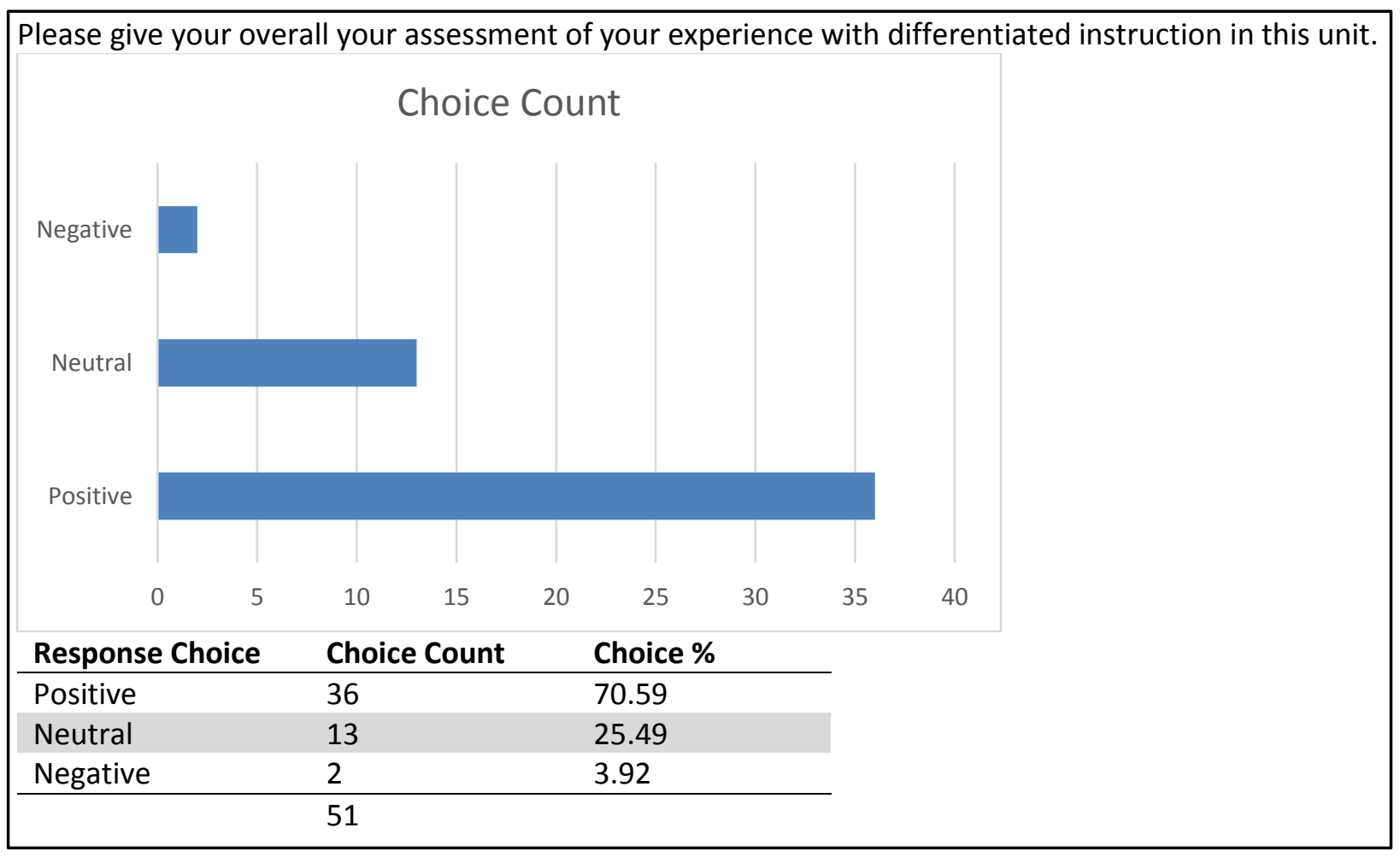


Figure 2 - Overall Assessment of DI by Students

Table 2 - t-Test: Two-Sample Assuming Equal Variances

\begin{tabular}{lll}
\hline & NDI & DI \\
\hline Mean & 19.8 & 19.5 \\
Variance & 33.5 & 45.3 \\
Observations & 72 & 55 \\
df & 125 & \\
Pooled sample variance & 38.589 & \\
t-stat & 0.242841 & \\
P(T<=t) two-tail & $\mathbf{0 . 8 0 8 5 2 7}$ & \\
t Critical two-tail & 1.979124 & \\
\hline
\end{tabular}

\section{Discussion}

Table 1 shows that students agreed that content was differentiated according to student readiness in the module, with $93 \%$ of respondents strongly agreeing or agreeing with statement 1 . The table also shows that students agreed that the learning process was differentiated according to readiness, with $91 \%$ of respondents strongly agreeing or agreeing with statement 2 . Students also noted that multiple assessments were used to guide instruction in the module, with $78 \%$ of respondents strongly agreeing or agreeing with statement 3 . Overall, the students had a positive perception of the use DI strategies in the module, with $71 \%$ of respondents giving a positive overall assessment.

While the survey responses indicate a positive student perception of the use of DI strategies, the independent samples t-test indicated that there was no statistically significant improvement in student performance as a result of these strategies $(\alpha=0.05<2 P(T \leq t) \cong 0.81)$.

The disparity between positive student perception of DI strategies and no significant improvement in student grades as a result of DI may be due to factors not anticipated prior to the initial design of this module. Firstly, as described in [9], students develop mastery of a topic by acquiring component skills, practice integrating these skills and knowing when to apply what they have learned. The component skills required for the module were assessed in the pre-class quiz and remedial content was assigned based on the quiz results, but there was no intervention put in place in the module if students had difficulty integrating the component skills while solving nodal/mesh problems. Another factor may be the need for more targeted feedback to students in response to their performance in the formative assessment. Currently, the response to the formative assessment is a homework assignment in which questions are selected based on student performance in the formative assessment, that is, there is no explicit feedback. As discussed in [9], there are two key features of effective feedback. The first is that effective feedback must communicate to students where they are relative to stated goals and what they need to do to improve. Secondly, effective feedback must be provided at a time and frequency when students are most likely to use it.

These two shortcomings in the initial design can be remedied by making modifications in the next iteration of module design. The first modification would be to design homework questions for students who perform poorly on the formative assessment in which the solution steps required for 
nodal/mesh analysis are explicitly stated and students are required to follow these steps to obtain the solution. This will aid students who exhibit lower levels of readiness in integrating component skills by including scaffolding mechanisms into the homework assignment. The second modification involves designing feedback responses to each formative assessment question. The content of this feedback would include commonly observed errors associated with each problem type along with the step-by-step solution. Also, student perception of the fairness of assigning homework assignments with different questions was not investigated. This aspect of student perception should be examined in the next offering of the course. Anecdotally, the current objections to these assignments were minimal. This was probably due to the homework assignments counting to only a small percentage of their overall grade.

\section{Conclusion}

Survey responses indicate that the majority students had a positive assessment of the DI strategies used in the module. This feedback serves as a source of encouragement to continue to improve DI delivery in future designs of the module and then to extend DI strategies to other modules in this course.

This initial experience in using DI has emphasized to me the importance of certain key instructional design criteria that are required for successful DI implementation in a college environment.

i. A learning module must have clearly defined objectives.

ii. The instructor must be willing to decompose their learning process into component skills in order to effectively differentiate based on student readiness.

iii. The instructor must be willing to go through at least one iteration of the process of "teach $\rightarrow$ assess $\rightarrow$-provide feedback $\rightarrow$ assign practice" prior to any summative assessment.

Criterion iii. is critically important because differentiation of content and learning process must be based on student performance data. Student data can be acquired from formative assessments and these assessments can be used as the basis for providing targeted feedback and assigning differentiated practice. It is my opinion that the largest obstacle to implementing DI strategies in college classroom environment is the implementation of criterion iii. This is because the data acquisition and analysis tasks associated with formative assessment, along with assigning the associated differentiated response can become prohibitively burdensome when there are large class sizes and/or few contact hours. To overcome this obstacle, an instructor must devise ways to provide feedback on larger scale than on an individual basis and devise methods to automate the differentiation process. Textbook publishers have begun to design personalized learning environments to accompany their textbooks. An example of this is the Mastering Engineering Series from Pearson [10]. Such environments will make the initial design of automated homework environments easier for instructors. Unfortunately, these learning environments are currently not available for many textbooks, which means the burden of design may still remain with the instructor.

\section{References}

[1] C. A. Tomlinson, The Differentiated Classroom. $2^{\text {nd }}$ edition, Alexandria, VA: Pearson, 
2016.

[2] C. A. Tomlinson et al., "Differentiating instruction in response to student readiness, interest, and learning profile in academically diverse classrooms: a review of literature," $J$. Educ. Gifted, vol. 27, No. 2/3, pp. 119-145, 2003.

[3] L. Vygotsky, Mind in Society: The Development of Higher Psychological Processes. Cambridge, MA, USA: Harvard University Press, 1978.

[4] P. Skomsvold, "Web Tables - Profile of Undergraduate Students: 2011-12," National Center for Education Statistics, Jessup, MD, USA, Rep. NCES 2015-167, 2014.

[5] T. Santangelo and C. A. Tomlinson, "The Application of Differentiated Instruction in Postsecondary Environments: Benefits, Challenges, and Future Directions," International Journal of Teaching and Learning in Higher Education, vol. 20, no. 3, pp. 307-323, 2009.

[6] M. Chamberlin and R. Powers, "The promise of differentiated instruction for enhancing the mathematical understandings of college students," Teaching Mathematics and Its Applications, vol. 29, pp. 113-139, April 2010.

[7] M. Dosch and M. Zidon, "The Course Fit Us': Differentiated Instruction in the College Classroom," International Journal of Teaching and Learning in Higher Education, vol. 26, no. 3, pp. 343-357, 2014.

[8] C. Tulbure, "The effects of differentiated approach in higher education: An experimental investigation," Procedia - Social and Behavioral Sciences, vol. 76, pp. 832-836, 2013.

[9] S. A. Ambrose et al., How Learning Works: Seven Research-Based Principles for Smart Teaching. San Francisco, CA: John Wiley \& Sons, 2010.

[10] "Mastering Engineering Features," Pearson: Mastering Engineering \& Computer Science, [Online]. Available:

https://www.pearsonmylabandmastering.com/northamerica/masteringengineering/educator s/features/index.html. [Accessed: Mar. 14, 2019]. 